\title{
Based Digital Signal Processor to Develop the M3S Novel Kernel System Chien-Chi Chen ${ }^{1}$, Jen-Chien Chien ${ }^{1}$, Meng-Lun Hsueh ${ }^{1}$, Jer-Junn Luh", Fok-Ching Chong ${ }^{1}$ \\ ${ }^{1}$ Institute of Electrical Engineering, National Taiwan University, Taiwan, R.O.C. \\ ${ }^{2}$ Department of Physical Medicine and Rehabilitation, National Taiwan University Hospital, Taiwan, R.O.C.
}

Abstract-The Multiple Masters Multiple Slave (M3S)

is an intelligent protocol. It provides the disable a concrete integral control for his movement, working, environment control and communication. This is an integrated real time control capability protocol. It is a plug and play device interface. Once plug- in, the new device with integrate and communicate with existing devices in use.

Our proposal is aim at this purpose. We intend to design and develop a M3S protocol that meets the requirement lay down in the M3S working group. Integrating different types of tools will absolutely bring lots of comforts to the disable. We set up the system using equipments purchase from the market, tested the system and ready it to be tested by other subgroups. Keywords: intelligent protocol, assistive devices, M3S

\section{INTRODUCTION}

Acute disabilities always need different types of assistive devices in their daily life. In the earlier time, each of these devices is designed for only one particular usage. Thus no considerations of interrelations among these tools were discussed. Because of this, an acute disable may have to used a joystick to manipulate his wheelchair, used a mouse to control computer, used a keyboard to control movement of mechanical arm in the access of objects and so forth.

However in early days of 1990 , the technical working committee 173 (TC-173/sc-1/wg-7) of ISO (International Organization for Standardization) spend a long time research on this issue. The committee suggested using serial interface protocol (ISO 7176-7) for integrating all types of assistive tools. The aim of this committee is to suggest a communication method to integrate all different types of tools for the disabilities. At the same time, the European Common Commission funded the research for M3S interface (Multiple Masters Multiple Slave). The M3S is an intelligent protocol. It provides the disable a concrete integral control for his movement, working, environment control and communication. This is an integrated real time control capability protocol. It is a plug and play device interface. Once plug- in, the new device with integrate and communicate with existing devices in use.

Our proposal is aim at this purpose. We intend to design and develop a M3S protocol that meets the requirement lay down in the M3S working group. Integrating different types of tools will absolutely bring lots of comforts to the disable.

\section{THEORY AND METHOD}

According to the norm of the M3S, this system includes three basic blocks which are input device, end-effectors and Control and Configuration
Module (CCM). Figure 1 is the M3S system contains input device, end-effectors and Control and Configuration Module (CCM).

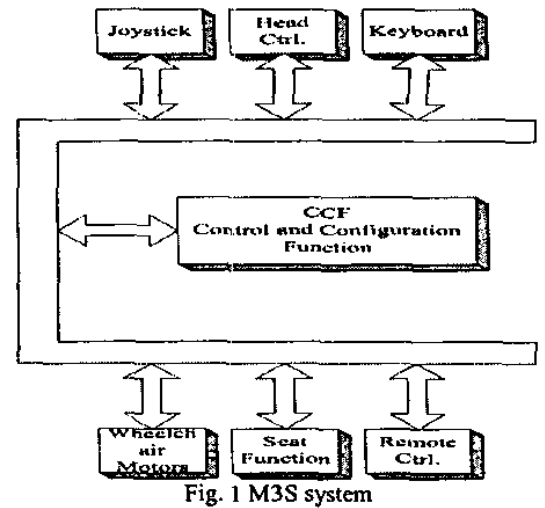

The core of the M3s system is CCM, and our goal is design this device which is called Intelligent Control Unit. We use the TMS320F243 digital processor which is produced by Texas Instruments Incorporated to control and switch the command of the different control units based on M3S framework and different condition in M3S environment.

There are three lays in M3S framework, and the three lays are application program layer, software abstraction layer and software abstraction layer, see the figure 2. The committee suggested using serial interface protocol (ISO 7176-7) for integrating all types of assistive tools. This system contains tow digital transmission line called CAN BUS (Control Area Network BUS), tow POWER BUS and tow SAF BUS.

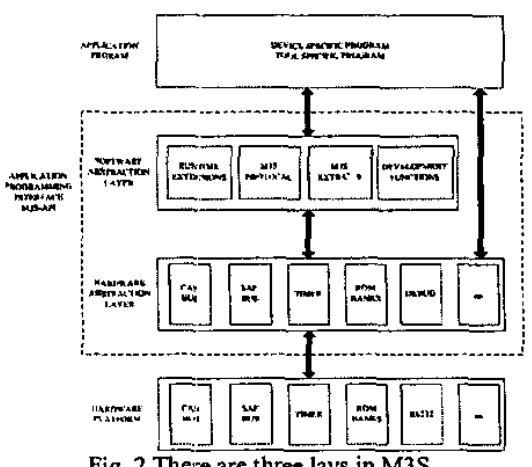

The structure of the TMS320F243 includes CAN bus - POW bus and SAF bus, see the figure 3 . This microprocessor also deals with external signals to control other systems. For example, it can convert analog signal from a joystick into digital signal. This process is that the signal. from a joystick goes through 
Analog-Digital converter and then goes to digital motor controller by way of this microprocessor. So this microprocessor can control a wheelchair goes forward or backward or leftward or rightward. Therefore this TMS320F243 is best choice for the M3S system.

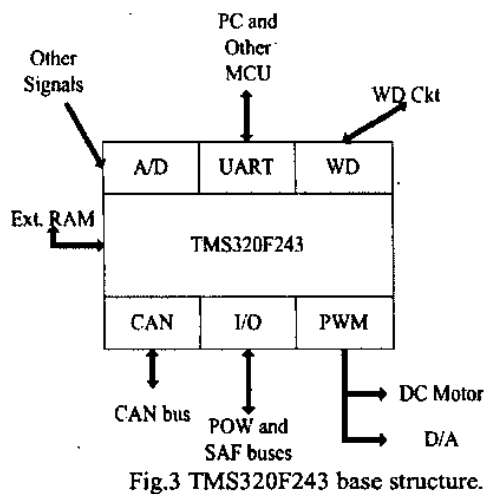

In the M3S system environment, the main three apparatuses connect with the M3S bus each other. M3S protocol that meets the requirement lay down in the M3S working group. Integrating different types of tools will absolutely bring lots of comforts to the disable.

Therefore, in order to design and integrate this system we should understand the Transmission Control Protocol of all kinds of signals in the M3S environment. The M3S BUS is based on the CAN BUS, and contains tow Power Line to apply the M3S BUS power and tow "Key-Line" and "Dead Man Switch-DMS " apparatuses. Linking digital control signals of all manner of apparatuses on the M3S is transmitted by the M3S BUS.

The CAN is a high security and a serial communication protocol application. The Transmission Control Protocol is widely made use of high speed and high security internet. For example, you can find it on the electrical device in the car, on the engine control unit and the sensor and so on. The transmitted rate is reached to $1 \mathrm{Mbit} / \mathrm{Sec}$ within $40 \mathrm{~m}$ network line. Because there are accurate debug mechanisms, high speed transmitted rate and real-time control characteristics, it is applicable to transmitted packed of the controlled wheelchair signal.

\section{RESULT}

We study all the related articles on of TMS 320F241, the specification of M3S and the regulation and the safety standard of Europe medical devices commission. In hardware, the M3S has finished and it can give the software the following function: transmit and receive input and output signal via CAN protocol remotely control device and operate the system configuration testing in coordination of the peripheral hardware apparatuses. Besides, it also can carry out the safety monitor through tow system safeguards in the M3S BUS to apply the requests of the M3S system kernel.
Clinical testing will help us modify and refine both the hardware and the firmware. We will combine with other $1 / O$ subsystems to have a total integrated system. Then the total system will be refined both in hardware and firmware to produce an ideal system compromise with the needs of the disables. However, to offer the best solution, we may install our self-developed API for different protocol eg. (TCP/IP).

\section{REFERENCE}

[1] M3S Consortium (http:/www.tno.nl/m3s). M3S, a general purpose Interface for the Rehabilitation environment. Proceedings 2nd ECART Conference. Stockholm, Sweden, 26-28 May 1993.

[2] M3S: the local network for electric wheelchairs and rehabilitation equipment Linnman, $S$. Rehabilitation Engineering, IEEE Transactions on [see also IEEE Trans. on Neural Systems and Rehabilitation Engineering] , Volume: 4 Issue: 3 , Sept. 1996 Page(s): $188-192$

[3] M3S-a standard communication architecture for rehabilitation applications Van Woerden, J.A.; Nelisse, M.W.; Perricos, C.; Jackson, R.D.; Davies, B.; Hibberd, R.D.; Banerjee, D. Computing \& Control Engineering Journal, Volume: 5 Issue: 5, Oct. 1994 Page(s): $213-218$

[4] The design of the M3S: a multiported shared-memory multiprocessor Sainrat, P.; Mzoughi, A.; Rochange, C.; Litaize, D. Supercomputing '92, Proceedings, 1992 Page(s): $326-335$ 